\title{
Epidemiology and treatment approaches in management of invasive fungal infections
}

This article was published in the following Dove Press journal:

Clinical Epidemiology

19 May 201 I

Number of times this article has been viewed

\author{
Jane Kriengkauykiat ${ }^{1,2}$ \\ James I Ito ${ }^{2}$ \\ Sanjeet S Dadwal ${ }^{2}$ \\ 'Department of Pharmacy, \\ ${ }^{2}$ Division of Infectious Diseases, \\ City of Hope, Duarte, CA, USA
}

Correspondence: James I Ito City of Hope, I500 E Duarte Rd, Duarte, CA 91706 , USA

Tel +l 6262564673 ext 62202

Fax + I 6263018954

Email jito@coh.org
Abstract: Over the past 20 years, the number of invasive fungal infections has continued to persist, due primarily to the increased numbers of patients subjected to severe immunosuppression. Despite the development of more active, less toxic antifungal agents and the standard use of antifungal prophylaxis, invasive fungal infections (especially invasive mold infections) continue to be a significant factor in hematopoietic cell and solid organ transplantation outcomes, resulting in high mortality rates. Since the use of fluconazole as standard prophylaxis in the hematopoietic cell transplantation setting, invasive candidiasis has come under control, but no mold-active antifungal agent (except for posaconazole in the setting of acute myelogenous leukemia and myelodysplastic syndrome) has been shown to improve the survival rate over fluconazole. With the advent of new azole and echinocandin agents, we have seen the emergence of more azole-resistant and echinocandin-resistant fungi. The recent increase in zygomycosis seen in the hematopoietic cell transplantation setting may be due to the increased use of voriconazole. This has implications for the empiric approach to pulmonary invasive mold infections when zygomycosis cannot be ruled out. It is imperative that an amphotericin B product, an antifungal that has never developed resistance in over 50 years, be initiated. The clinical presentations of invasive mold infections and invasive candidiasis can be nonspecific and the diagnostic tests insensitive, so a high index of suspicion and immediate initiation of empiric therapy is required. Unfortunately, our currently available serologic tests do not predict infection ahead of disease, and, therefore cannot be used to initiate "preemptive" therapy. Also, the Aspergillus galactomannan test gives a false negative result in patients receiving antimold prophylaxis, ie, virtually all of our patients with hematologic malignancy and hematopoietic cell transplant recipients. We may eventually be able to select patients at highest risk for invasive fungal infections for prophylaxis by genetic testing. However, with our current armamentarium of antifungal agents and widespread use of prophylaxis in high-risk groups (hematologic malignancy, hematopoietic cell transplantation), we continue to see high incidence and mortality rates, and our future hope lies in reversing the immunosuppression or augmenting the immune system of these severely immunocompromised hosts by developing and utilizing immunotherapy, immunoprophylaxis, and vaccines.

Keywords: invasive fungal infections, antifungal agents, immunosuppression

\section{Introduction}

Invasive fungal infections are a growing problem in our severely immunocompromised patients. Hematopoietic cell and solid organ transplantations continue to increase, and despite recent development of more active and less toxic antifungal agents, mortality rates from invasive fungal infections remain unacceptably high. In this article we review invasive fungal infections in immunocompromised hosts. The focus will be on invasive mold infections, (particularly invasive aspergillosis) and invasive candidiasis, and on 
immunocompromised hosts, including neutropenic patients with hematologic malignancy, hematopoietic cell transplant recipients, solid organ transplant recipients, and high-risk intensive care unit patients. Specifically, the following topics will be reviewed: epidemiology, including incidence and mortality rates for invasive fungal infections; emerging resistance patterns; high-risk groups and risk factors; clinical presentation of each type of invasive fungal infection; diagnosis; antifungal treatment options; management; and future developments in the treatment and prevention of invasive fungal infections.

\section{Epidemiology}

The epidemiology of invasive fungal infections has been difficult to glean from the literature because of the different definitions used, the different risk groups studied, and variation from institution to institution. To date, the most comprehensive multicenter epidemiologic surveillance study of invasive fungal infections in transplantation has been from the Transplant-Associated Infection Surveillance Network (TRANSNET) database. ${ }^{1-4}$ TRANSNET is a network of 23 US transplant centers performing hematopoietic cell and/or solid organ transplantations. Incidence, clinical and diagnostic information, and outcomes such as 12-month (and 3-month for hematopoietic cell transplant) mortality rates were evaluated. ${ }^{2,4}$ The database consists of invasive fungal infections occurring between 2001 and 2006. Prior to this period, the overall incidence of invasive fungal infection was $18 \%$, based on data from a single US center in a placebo-controlled group not on antifungal prophylaxis. ${ }^{5}$ According to TRANSNET data, there were 983 proven and probable cases of invasive fungal infection in hematopoietic cell transplant recipients, comprising of $21 \%$ autologous, $38 \%$ matched-related, 34\% matched-unrelated, and $6 \%$ mismatched-related transplants. The overall incidence during a 12-month period for invasive fungal infections among hematopoietic cell transplant recipients was 3.4\% (range $0.9 \%-13.2 \%)^{2}{ }^{2}$ This lower incidence is likely due to the now standard use of antifungal prophylaxis in hematopoietic cell transplantation. The incidence of invasive fungal infections was lowest for autologous hematopoietic cell transplants (1.2\%), and increased for matched-related donor $(5.8 \%)$, matched-unrelated donor (7.7\%), and mismatched-related donor $(8.1 \%)$. There are 3 phases of hematopoietic cell transplantation, ie, phase I (pre-engraftment), phase II (postengraftment, $<100$ days posttransplant), and phase III (late phase, $>100$ days posttransplant). ${ }^{6}$ The majority of invasive fungal infections occurred during phase II and phase III. TRANSNET data revealed an overall 3-month invasive fungal infection mortality rate of $51 \% .^{2}$ The 12-month mortality rate for overall invasive fungal infection was not reported. Other studies have reported the overall median 12-month mortality rate to be approximately $80 \%$ for all invasive fungal infections in hematopoietic cell transplantation patients. ${ }^{7}$

In the TRANSNET database, there were 1063 proven and probable cases of invasive fungal infection in solid organ transplant recipients. ${ }^{4}$ The overall incidence of invasive fungal infection was $3.1 \%$ in a 12 -month period, similar to that for hematopoietic cell transplantation. ${ }^{4}$ Historically, the incidence has ranged from $5.6 \%$ to $10.9 \%,{ }^{8}$ and varies according to transplant type. ${ }^{9}$ The highest incidence for fungal infections was with liver transplant $(7 \%-42 \%)$, followed by pancreas (18\%-38\%), heart and heart-lung (15\%-35\%), and the lowest with kidney transplant $(0 \%-14 \%) .{ }^{9}$ The addition of antifungal prophylaxis has lowered the incidence of invasive fungal infection in solid organ transplantation. In comparison with the older studies, the more recent TRANSNET data demonstrated small bowel transplants as having the highest risk of invasive fungal infection at $11.6 \%$, followed by lung and heart-lung transplants $8.6 \%$, liver $4.7 \%$, and pancreas and pancreas-kidney $4 \% .{ }^{4}$ Heart transplant recipients had a lower risk at $3.4 \%$, and kidney had the least risk at $1.3 \%$. The majority of invasive fungal infections occurred more than 90 days posttransplant. Overall 12-month mortality for invasive fungal infection was not presented in the TRANSNET data.

Currently there are no large multicenter, prospective, surveillance studies in nontransplant patients with hematologic malignancy, such as acute myelogenous leukemia and myelodysplastic syndrome. However, data are available from prophylactic trials. ${ }^{10,11}$ The incidence of invasive fungal infections was $2 \%-8 \%$ depending on the antifungal prophylaxis regimen used. ${ }^{10,11}$ Comparison with older studies is difficult. The data from clinical trials varies due to the different definitions of invasive fungal infection. One prophylactic study reported invasive fungal infection rates of $20 \%$ (proven and probable cases) in the placebo $\operatorname{arm}^{12}$ and $4.4 \%$ (proven deepseated invasive fungal infections) in another study. ${ }^{13}$ In the latter study, the 2-month mortality rate for invasive fungal infection was $56 \% .{ }^{13}$ In a recent clinical trial, ${ }^{10}$ mortality for invasive fungal infection was not evaluated. However, overall 100-day mortality was evaluated, and was $22 \%$ in a fluconazole / itraconazole prophylaxis group and $14 \%$ in a posaconazole prophylaxis group. ${ }^{10}$

The overall incidence of invasive fungal infections in prospective surveillance data that directly compare high-risk 
groups is limited, and may differ by institution. Autopsy data are available from a single-center review (2707 of 10,151 patients) for 1993-2005. ${ }^{14}$ Patients with the following underlying diseases were included: hematologic malignancy, solid tumors, transplant (either solid organ or hematopoietic cell transplantation), acquired immunodeficiency syndrome, and other diagnoses. Overall, the prevalence of invasive fungal infections was $8.2 \%$. Invasive fungal infection rates were tabulated by time periods in order to evaluate trends, and were as follows: 1993-1996 (6.6\%), 1997-2000 (8.6\%), and 2001-2005 (10.4\%). The highest prevalence was found in patients with hematologic malignancy (33\%), followed by transplant (22.9\%), acquired immunodeficiency syndrome $(19.7 \%)$, solid tumors $(4.8 \%)$, followed by other diagnoses (3.5\%). The most common infecting fungal organisms were Aspergillus species, then Candida species. Other fungal organisms (eg, Cryptococcus species and Zygomycetes) were all found in approximately $1 \%$ or less of the cases reviewed. The study did note that the prevalence of invasive fungal infection decreased over time in the transplant group when comparing the 1997-2000 and 2001-2005 periods. As noted earlier, this is most likely attributable to the use of antifungal prophylaxis in the transplant population.

\section{Aspergillosis}

During the 1990s, in patients who did not receive antifungal prophylaxis, invasive fungal infections caused by Candida species were most frequent $(18 \%)$, followed by invasive fungal infections caused by Aspergillus species (1.4\%). This pattern has changed over the past two decades. The introduction of fluconazole prophylaxis, which prevented many infections caused by Candida species, altered the epidemiology of invasive fungal infection. According to TRANSNET data, the overall incidence of invasive aspergillosis is $1.6 \%$. $^{2}$ However, invasive aspergillosis is now the most common invasive fungal infection in hematopoietic cell transplantation (43\%, Table 1). Aspergillus fumigatus was the most common Aspergillus species (44\%). ${ }^{2}$ The median time to infection occurred at the end of the late posthematopoietic cell transplantation phase II (day 99). In the solid organ transplantation group, the incidence of invasive aspergillosis was $0.7 \%$, and accounted for $18.8 \%$ of invasive fungal infections in the solid organ transplant group. ${ }^{4}$ It was most frequent in lung transplant (44\%), whereas it was the second or third most frequent invasive fungal infection in other transplant types $(5 \%-23 \%)$. The median time to onset of invasive aspergillosis was 184 days. For nontransplant patients with hematologic malignancies, data from antifungal prophylaxis clinical trials reported an incidence for invasive aspergillosis of 1\%-7\% with azole prophylaxis ${ }^{10}$ and $4 \%-5 \%$ with prophylaxis using amphotericin B lipid formulations. ${ }^{10,11}$ The majority of invasive fungal infections were also due to invasive aspergillosis (33\%-69\%). In critically ill patients, the infection rate for invasive aspergillosis has been reported to be $2.6 \%$, and the proportion of invasive fungal infections caused by invasive aspergillosis was $11 \%{ }^{15}$

Similar to the changing epidemiology of invasive fungal infections over recent years, mortality rates have also changed. The 3-month overall invasive aspergillosis mortality rate had been $42 \%$ with conventional amphotericin $\mathrm{B},{ }^{16}$ and $68 \%$ in hematopoietic cell transplantation. ${ }^{7}$ The 1 -year mortality rates in hematopoietic cell transplantation associated with invasive aspergillosis during the 1990 s was $80 \% .^{7}$ The 12 -month mortality rates for transplant patients in the most recent TRANSNET data were $75 \%$ for hematopoietic cell transplantation and $41 \%$ for solid organ transplantation. ${ }^{2,4}$ Another TRANSNET data report indicated 3-month mortality rates for hematopoietic cell transplantation of 57.5\% (239/415) and for solid organ transplantation of $34.4 \%(78 / 227) .{ }^{1}$ The same report by TRANSNET did evaluate mortality rate over time. ${ }^{1}$ Mortality rates in hematopoietic cell and solid organ transplant recipients were shown to decrease over time from approximately $72 \%$ and $43 \%$ in 2001 to $55 \%$ and $27 \%$ in 2005-2006, respectively. Allogeneic hematopoietic cell transplantation, neutropenia, cytomegalovirus disease, renal or hepatic insufficiency, and corticosteroid use were associated with higher mortality rates. ${ }^{1}$ The species of Aspergillus also plays a role in mortality. A. fumigatus was associated with a 63\% 3-month mortality rate compared with Aspergillus terreus, a much more antifungal-resistant species, with a reported mortality rate of $100 \%{ }^{17}$

\section{Invasive candidiasis}

The epidemiology of invasive candidiasis has also changed. In the $1990 \mathrm{~s}$, the incidence of invasive candidiasis was reported at one institution to be $15 \%$, and accounted for $88 \%$ of all invasive fungal infections in hematopoietic cell

Table I Proportion of invasive fungal infections reported in the literature

\begin{tabular}{llllll}
\hline & IA & Zygomycosis & IC & Other & Reference(s) \\
\hline HCT & $43 \%$ & $8 \%$ & $28 \%$ & $15 \%$ & 2 \\
SOT & $18.8 \%$ & $2.3 \%$ & $52.9 \%$ & $19 \%$ & 4 \\
HM & $33 \%-69 \%$ & - & $13.5 \%-44 \%$ & - & 10,11 \\
ICU & $11 \%$ & - & $79 \%$ & $10 \%$ & 15 \\
\hline
\end{tabular}

Abbreviations: HCT, hematopoietic cell transplantation; HM, hematologic malignancy; IA, invasive aspergillosis; IC, invasive candidiasis; ICU, intensive care unit; SOT, solid organ transplantation. 
transplantation. ${ }^{5}$ In the most recent data from TRANSNET, this proportion has changed. The incidence of invasive candidiasis is now $1.1 \%$ for hematopoietic cell transplantation and just under $2 \%$ for solid organ transplantation. ${ }^{2,4}$ In hematopoietic cell transplantation and lung transplantation, invasive candidiasis is the next largest proportion of invasive fungal infections after invasive aspergillosis, at $28 \%$ and $23 \%$, respectively. ${ }^{2,4}$ In solid organ transplantation, approximately half (52.9\%) of invasive fungal infection cases were invasive candidiasis. ${ }^{4}$ Invasive candidiasis made up the highest proportion of invasive fungal infections across the remaining transplant types. Invasive candidiasis generally occurred in the posthematopoietic cell transplantation engraftment phase II (day 61), earlier than the onset of other invasive fungal infections. Similar to hematopoietic cell transplantation, the onset of invasive candidiasis in solid organ transplantation followed a similar pattern, with an earlier median onset (103 days) posttransplant compared with other invasive fungal infections. The data from clinical trials for patients with hematologic malignancy demonstrated invasive candidiasis incidences of $1 \%-3 \%$, and invasive candidiasis comprised the next largest proportion of invasive fungal infections $(13.5 \%-44 \%)$ after invasive aspergillosis. ${ }^{10,11}$ Breakthrough Candida infections on antifungal prophylaxis reported in the literature are of importance to the changing epidemiology of invasive candidiasis. Micafungin prophylaxis has been associated with invasive candidiasis caused by Candida parapsilosis. ${ }^{18}$

Critically ill patients in intensive care are at an increased risk of invasive candidiasis. ${ }^{19-21}$ In the intensive care unit, invasive candidiasis is the third most common cause of infections globally (17\%), and the second most common cause in the US (18.2\%) after infections caused by Staphylococcus aureus $(26.9 \%) .{ }^{15}$ The proportion of invasive fungal infections caused by Candida species was 79\%. In the US, Candida species are also the third most common cause of catheter-related blood stream infections. ${ }^{22}$ C. albicans is the most common Candida species (50\%-60\%), followed by C. glabrata (15\%-20\%), C. parapsilosis (10\%-20\%), and C. tropicalis $(6 \%-12 \%)$, and the remainder are made up by C. krusei, C. guillermondii, and C. lusitaniae (1.3\%). ${ }^{19}$

Historically, 3-month mortality due to invasive candidiasis was at least $50 \%$ in critically ill patients. ${ }^{23}$ In more recent data, the reported 2-month mortality was $42.6 \%{ }^{24}$ The 12-month mortality in hematopoietic cell transplantation was $66.4 \%{ }^{2}$ and $34 \%$ in solid organ transplantation. ${ }^{4}$ Outcomes also differed with Candida species. The overall 3-month mortality among all patients with invasive candidiasis ranged from highest with C. krusei (52.9\%) to lowest with C. parapsilosis $(23.7 \%) .{ }^{21}$

\section{Zygomycosis}

According to TRANSNET data, the proportion of invasive fungal infections caused by zygomycosis is $8 \%$ in hematopoietic cell transplantation ${ }^{2}$ and $2.3 \%$ in solid organ transplantation. ${ }^{4}$ The incidence in hematopoietic cell and solid organ transplantation was approximately $0.3 \%$ and $0.1 \%$, respectively. ${ }^{2,4}$ Most infections occurred after day 100 after posthematopoietic cell transplantation and at median day of 312 postsolid organ transplantation. The overall 3-month and 12-month mortality rates in hematopoietic cell transplantation were approximately $64 \%-72 \%$. $^{2,25}$ There is also an increasing rate of zygomycosis infection in hematopoietic cell transplantation recipients. ${ }^{3}$ In 2001 , the 1 -year incidence of zygomycosis was $1.7 / 1000$ patients. In 2004 , it increased to $6.2 / 1000$ patients. Another study found similar results with the advent of newer antifungals, such as voriconazole and caspofungin, correlating with significant increases in zygomycosis. ${ }^{26}$ The rates increased from $0.57 / 100,000$ admissions prior to 2003 to $6.3 / 100,000$ admissions after 2003. These increasing trends likely correlate with recent reports of breakthrough infections in those receiving prophylaxis with newer antifungals, such as voriconazole and echinocandins, in hematopoietic cell transplantation. ${ }^{26-29}$

\section{Other invasive fungal infections}

Other invasive fungal infections in the transplant population occur less frequently than invasive aspergillosis, invasive candidiasis, and zygomycosis. In the hematopoietic cell transplantation population, the incidences for non-Aspergillus and unspecified mold were approximately $0.3 \%$ and $0.2 \%$, respectively. ${ }^{2}$ The proportion of invasive fungal infections caused by Fusarium species was 3\%. Acremonium, Alternaria, and Scedosporium species accounted for $7 \%$. Unspecified molds accounted for $6 \%$ of invasive fungal infections. The majority of these infections occurred after day 100 posthematopoietic cell transplantation. ${ }^{2}$ In the solid organ transplantation population, the incidences were $0.1 \%-0.2 \%$ for other molds and endemic invasive fungal infections. Cryptococcus infections comprised $8 \%$ of all invasive fungal infections, and other molds comprised $6.5 \%$. Endemic fungal infections comprised $5.3 \%$ of all invasive fungal infections. ${ }^{4}$ In intensive care patients, infections caused by other fungi occurred at a rate of $2.2 \%$, representing $10 \%$ of all invasive fungal infections. ${ }^{15}$ 
Mortality rates for molds other than Aspergillus species and Zygomycetes vary according to pathogen. The highest mortality rate is seen with fusariosis in hematopoietic cell transplantation $(93.7 \%))^{2}$ The 12-month mortality among solid organ transplant recipients was $39 \%$ for other molds, and $27 \%$ for Cryptococcus. ${ }^{4}$ Other studies have reported 3 -month mortality rates of $80 \%$ in hematopoietic cell transplantation from infections due to Fusarium and Scedosporium species. ${ }^{25}$

\section{Resistance and trends}

The potential for increasing antifungal resistance has long been a concern in the treatment of invasive fungal infections. Fungal pathogens can exhibit various mechanisms of resistance. The most common for antifungals are target mutations or change in expression of genes, such as overexpression of the efflux pumps that remove antifungals..$^{30,31}$

\section{Candida and resistance}

Azole resistance was first noted in Candida species in patients with acquired immunodeficiency syndrome. ${ }^{32}$ There was a total of 348 isolates tested against fluconazole, and 33\% were found to be resistant compared with $11 \%$ in isolates from patients without acquired immunodeficiency syndrome. This was related to prolonged exposure and use for such conditions as Candida esophagitis. A similar concern exists for transplant and other immunocompromised patients because they may be exposed to prolonged use of azole antifungal agents as well. ${ }^{33}$

Overexpression of efflux genes is the most common mechanism of resistance to azoles in Candida species, and has also been associated with cross-resistance within the class. ${ }^{30,31}$ Progressive loss of echinocandin activity has been observed in Candida species when exposed to prolonged echinocandin use. ${ }^{34}$ The most common mechanism of echinocandin resistance is associated with mutation in the FKS1 gene, a gene that produces the FKS1 protein for $\beta-1,3-\mathrm{D}$ glucan synthase.

\section{Aspergillus and resistance}

Similar to Candida species, the mechanism of resistance in molds, such as Aspergillus species, is due to point mutations and efflux pump overexpression; however, the targets are different. ${ }^{34}$ The CYP51 gene (important for encoding 14- $\alpha$-sterol demethylase) target mutation results in decreased azole susceptibility, ${ }^{34,35}$ and may lead to crossresistance between itraconazole and posaconazole, but not for echinocandins ${ }^{34}$ Overexpression of multidrug-resistant efflux pumps confers decreased susceptibility in A. fumigatus, ${ }^{36}$ and has been shown to be inducible with voriconazole treatment in a mouse biofilm model.

\section{Resistance patterns}

Overall susceptibility patterns have also been changing over time due to use of prophylactic antifungal agents. In a large collection of 519 A. fumigatus isolates, resistance to azoles increased between 1997 and $2007 .{ }^{37}$ There was no resistance found in isolates from 1997, and only 3\%-7\% resistance in the years prior to 2004 . Between 2004 and 2007, resistance increased each year to $17 \%$ in 2007 . Each year after 2004, multiazole resistance increased. In another study, the epidemiology of 269 oral Candida isolates was evaluated in patients with hematologic malignancies, and in those with head and neck and solid tumors. ${ }^{38}$ C. albicans comprised the majority $(74 \%)$ of isolates. Resistance patterns for azoles were as follows: fluconazole $4.5 \%$ (C. albicans, C. glabrata, C. krusei), itraconazole $11.7 \%$ (C. albicans, C. glabrata, C. tropicalis), and voriconazole $0.75 \%$ (C. glabrata). Resistance to caspofungin was $4.1 \%$ (C. albicans, C. parapsilosis) and 10.2\% had intermediate susceptibility. None were resistant to amphotericin B.

\section{High-risk groups}

Immunocompromised patients at highest risk for developing invasive fungal infection include hematopoietic cell transplant recipients, solid organ transplant recipients, patients with hematologic malignancy, and patients with other severe immunologic conditions. In hematopoietic cell transplant recipients, there are 3 phases of risk for invasive fungal infections. ${ }^{6}$ Phase I is marked by neutropenia and barrier breakdown. In phase II, patients are at risk for invasive fungal infections due to impaired cellular immunity. Although CD8 T cells are increasing postengraftment, specific antifungal $\mathrm{T}$ cell immune reconstitution is not complete until months to a year after hematopoietic cell transplantation. ${ }^{39}$ Acute graft versus host disease and its treatment with corticosteroids are the major contributors to the risk of invasive fungal infection during this phase. In phase III, chronic graft versus host disease and corticosteroid therapy remain significant risk factors for continuing impaired cellular immunity.

Solid organ transplant recipients are at increased risk of invasive fungal infection due to the long-term immunosuppressive therapies that may be required to prevent or treat rejection. ${ }^{40}$ In solid organ transplantation, periods of 
infection risk posttransplant have also been noted. During the early posttransplant period (1 to 2 months), Aspergillus pneumonia can occur. Up to 6 months posttransplantation, chronic rejection is a risk factor for invasive fungal infections. Subsequently, beyond six months posttransplantation, the risk is mainly due to residual immunosuppression, exposure to $\mathrm{T}$ cell-depleting agents, and graft function.

For patients with hematologic malignancy, the main risk factor is prolonged neutropenia after immunosuppressive chemotherapy, such as induction, reinduction, and consolidation chemotherapy. ${ }^{10,41,42}$ For critically ill patients, the main risk factors include severe disease and long-term stay in an intensive care unit. $^{20}$

\section{Risk factors}

There are risk factors specific for each invasive fungal infection (Table 2). Risk factors for invasive aspergillosis include graft versus host disease, corticosteroids, neutropenia, cytomegalovirus infection, and prior lung disease. Risk factors for invasive candidiasis include neutropenia, central venous catheter, total parental nutrition, corticosteroids, gastrointestinal surgery, prolonged intensive care stay, and broad spectrum antibiotics. These risk factors relate to impairment of the host immune system, genetic predisposition, and environmental exposure.

Table 2 Risk factors for invasive fungal infections

\begin{tabular}{ll}
\hline & Risk factors \\
\hline IFI & Host predisposition \\
& Neutropenia $\geq 3$ weeks \\
& Environmental factors \\
& GVHD (acute grades $2-4$ or chronic) \\
& HCT type (mismatched-related donor at greatest risk) \\
& Underlying hematologic disease (MDS or AML) \\
& Corticosteroid (dose and duration) \\
& T cell-depleting therapy \\
& CMV infection \\
& Ganciclovir use \\
& Polymorphisms (TLR4, TNF, or IL-I0) \\
& HCT in nonlaminar air flow room \\
& Colonization \\
& Presence of central venous catheter \\
& Hemodialysis \\
& Surgery (complicated or repeated abdominal) \\
& Clinical unstable presentation (acute renal failure, shock, \\
& disseminated intravascular coagulation) \\
& Antianerobic antibiotic agents \\
& Total parental nutrition or intralipid agents \\
& Prolonged ICU stay
\end{tabular}

Abbreviations: AML, acute myelogenous leukemia; CMV, cytomegalovirus; GVHD, graft versus host disease; $\mathrm{HCT}$, hematopoietic cell transplantation; $\mathrm{HM}$, hematologic malignancy; IA, invasive aspergillosis; IC, invasive candidiasis; ICU, intensive care unit; IFI, invasive fungal infection; IL-10, interleukin-10; MDS, myelodysplastic syndrome; SOT, solid organ transplantation; TLR4, toll-like receptor 4; TNF, tumor necrosis factor.

\section{Host/immune system}

It has long been observed that the longer and more profound the neutropenia, the more at risk the patient will be for invasive fungal infections. ${ }^{43}$ Circulating neutrophils have been demonstrated to have an inverse relationship with prevalence of infections. ${ }^{44,45}$ The duration of neutropenia was found to be the most important factor, especially when persisting for 3 weeks or more. ${ }^{43,44}$ In addition to risk for invasive fungal infections, recovery of neutrophil count is important in patient outcomes.

\section{Invasive aspergillosis}

One study found that risk factors varied slightly depending on when infection occurred, ie, within 40 days or after 40 days posthematopoietic cell transplantation. ${ }^{46}$ Risk factors related to the host that were similar for both early and later onset of infection were underlying disease, donor type (autologous $<$ matched-related $<$ matched-unrelated $<$ mismatch-related), and graft versus host disease. There were additional host immune factors found for infection risk 40 days posttransplant, ie, neutropenia and corticosteroid use. However, it is often difficult to determine if the risk of invasive aspergillosis is due to graft versus host disease itself or due to the corticosteroids used to treat the graft versus host disease. Compared with patients who did not have invasive aspergillosis, patients with hematologic malignancy in "non-first remission" were 8.9 times more at risk for onset of infection within 40 days posthematopoietic cell transplantation, and 3.06 times more at risk 40 days posttransplant. Mismatched-related donor hematopoietic cell transplantation has a significantly higher risk in the early posttransplant period, whereas after 40 days, the risk is higher with unrelated donor transplants. For invasive aspergillosis, the presence of graft versus host disease grades $2-4$ had a relative risk of 2.6, neutropenia 5.9, and corticosteroid use 3.1 .

Other studies have reported similar findings with regard to risk factors for invasive fungal infection. ${ }^{47}$ Myelodysplastic syndrome compared with other underlying hematologic diseases (including acute myelogenous leukemia, chronic myelogenous leukemia, acute lymphocytic leukemia, and multiple myeloma) and unrelated donor hematopoietic cell transplantation compared with sibling donor transplantation were significant risk factors for invasive fungal infection. Grades 3-4 acute graft versus host disease and extensive chronic graft versus host disease were also found to be significant risk factors. ${ }^{47,48}$ T cell-depleting therapies (antithymocyte globulin or alemtuzumab) delay immune recovery and also increase the risk of invasive aspergillosis. ${ }^{6,48-51}$ 
Chronic treatment for graft versus host disease with corticosteroids places hematopoietic cell transplantation recipients at increased risk of infection. Risk was found to be associated with the duration and intensity of the corticosteroid regimen. ${ }^{52}$ The greatest risk for infection was found to be within 2 weeks of high prednisone-equivalent doses of $1 \mathrm{mg} / \mathrm{kg} /$ day or greater. This extended to 4 weeks for doses of $0.25-1 \mathrm{mg} / \mathrm{kg} /$ day. Other immunosuppressants, such as daclizumab and infliximab, have been significantly associated with invasive fungal infection. ${ }^{53,54}$

Cytomegalovirus infection has been associated with risk for invasive fungal infection. ${ }^{49,52}$ The virus itself is marrow-suppressive, as is the drug therapy commonly used to treat cytomegalovirus, ie, ganciclovir. Cytomegalovirus suppresses cellular and humoral immunity, causes abnormalities in lymphocytes and monocytes, and suppresses antigenspecific cytotoxic T lymphocytes. ${ }^{49}$ Ganciclovir (an antiviral agent with marrow-suppressive effects) has been associated with a significant risk for invasive aspergillosis, with a hazard ratio of 13.5, even higher than the use of high-dose corticosteroids, graft versus host disease, or neutropenia. ${ }^{52}$

\section{Genetic predisposition}

The study of genetic risk factors as they relate to development of invasive fungal infection is becoming increasingly important to evaluate. This is not only to select those patients who are at high risk for invasive fungal infection for prophylaxis, but to illuminate the immunology and pathophysiology of invasive fungal infections. Invasive aspergillosis has been studied the most in this regard. Polymorphisms in toll-like receptors (TLRs) and tumor necrosis factor (TNF)- $\alpha$ are considered to be one of the more significant genetic factors associated with infection. ${ }^{55,56}$

TLRs are immune cell surface proteins that recognize fungal pathogens. TLR polymorphisms have been associated with different types of infections. ${ }^{57}$ Two donor TLR4 haplotypes, $\mathrm{S} 3$ and $\mathrm{S} 4$, were found to have increased risk for invasive aspergillosis, with hazard ratios of 2.2 and 6.2, respectively. ${ }^{55}$

TNF- $\alpha$ is secreted by macrophages and activated T lymphocytes during fungal infection. ${ }^{56} \mathrm{TNF}-\alpha$ acts through TNF receptor 1 (TNFR1) to trigger a proinflammatory response. Single nucleotide polymorphisms in the TNFR1 gene have been associated with susceptibility to invasive aspergillosis, with odds ratios of 1.7-1.9. It was demonstrated that significantly lower TNFR1 mRNA expression occurred in patients with invasive aspergillosis compared with noninfected patients with single nucleotide polymorphisms in TNFR1.
Single nucleotide polymorphisms in the proximal region and haplotypes of the interleukin (IL)-10 promoter gene have also been evaluated. IL-10 is a typical Th2 regulator cytokine. ${ }^{58}$ Increased production of IL-10 has been shown to be associated with invasive aspergillosis. Thus, single nucleotide polymorphisms may affect transcription of IL-10 genes and thus production of IL-10, as would certain haplotypes. One study found an increased incidence of invasive aspergillosis with increased occurrence $(11.5-19.7 \%)^{58}$ of single nucleotide polymorphisms, with a hazard ratio of 9.3 .

\section{Environmental factors}

Environmental factors can play a role in the risk of invasive fungal infection in high-risk patients. In regards to hematopoietic cell transplantation, it was found that transplants that occurred outside laminar air flow rooms had an increased risk of invasive aspergillosis during the early posthematopoietic cell transplantation period, within 40 days after transplant. ${ }^{46}$ The risk for infection was 5.6 times higher than for transplants occurring within a laminar air flow room. For infections occurring beyond 40 days posttransplant, environmental factors were also found to be significant. This is important because most hematopoietic cell transplant recipients are discharged from the hospital (and their HEPA [Health Enhancing Physical Activity]-filtered environment) by day 40 when they are at high risk for invasive mold infection. Hence, this may explain the peak incidence of invasive aspergillosis that was observed at day 99 in the recent TRANSNET data. ${ }^{2}$ Construction placed patients at higher risk for infection by 1.8 times. ${ }^{46}$ Seasonality can also play a role in the risk of invasive fungal infection. ${ }^{46}$ One study found the summer months to be associated with the highest risk for invasive aspergillosis. ${ }^{59}$

\section{Invasive candidiasis}

Another high-risk group for fungal infections is critically ill patients. These patients are mainly at increased risk of invasive candidiasis. There are multiple risk factors that have been associated with invasive candidiasis, ie, colonization, presence of a central venous catheter, hemodialysis, and surgery, particularly complicated and repeated abdominal surgery. ${ }^{20,60}$ Patients who are clinically unstable are at increased risk for invasive candidiasis, ie, those with acute renal failure, shock, and disseminated intravascular coagulation. ${ }^{60}$ Certain medications have been associated with increased risk for candidemia. These include antianerobic antibiotics (2.2 relative risk) such as carbapenems, metronidazole, clindamycin, and piperacillin/tazobactam. However, there was no increased 
risk with individual antibiotics, such as aminoglycosides, cephalosporins, and quinolones. Of those patients who did not receive an antibacterial antibiotic, none developed candidemia. This is likely related to replacement of the normal gastrointestinal flora with Candida species. Other agents associated with invasive candidiasis are parenteral nutrition and intralipid agents.

\section{Clinical presentation of invasive fungal infections}

Manifestations of invasive fungal infection in the immunocompromised host may range from fever of unknown etiology to symptoms and signs referable to a specific organ system affected by the fungal pathogen. ${ }^{61}$ At the other end of the spectrum are patients with no symptoms or signs, primarily due to the underlying immunosuppression, steroid use, and neutropenia. ${ }^{62,63}$

\section{Candidemia and visceral (chronic disseminated) candidiasis}

Fever persisting despite appropriate empiric antibacterial therapy during neutropenia is one of the most common manifestations of candidemia in immunocompromised patients; up to $88 \%$ of episodes in one series ${ }^{64}$ and $99 \%$ in another. ${ }^{65}$ Sepsis syndrome/septic shock can be an initial presentation of candidemia with multiorgan dysfunction. Skin and soft tissue involvement usually manifests as a rash that may have a variable presentation, ranging from maculopapular erythematous to nodular lesions, and may be painful. The lesions may appear similar to ecthyma gangrenosum. ${ }^{66}$ Muscle pain/ myositis may be present. Candida endophthalmitis may be asymptomatic (depending on location of lesions), but may manifest with blurred vision, creamy white retinal lesions that may evolve to retinal necrosis evident on funduscopic examination. Vitritis and uveitis can be seen. ${ }^{67}$ Cardiac involvement can be in the form of infective endocarditis of a native or prosthetic valve, pericarditis, ${ }^{68}$ and septic thrombophlebitis, usually in the setting of indwelling central venous catheters.

Candidemia can be associated with dissemination to deep organs causing visceral (chronic disseminated) candidiasis, identified most commonly in the setting of resolving neutropenia after cytotoxic chemotherapy in acute leukemia and hematopoietic cell transplantation. This syndrome is associated with a low yield of fungal isolates on blood culture. With resolution of neutropenia, the patient may present with fever, right upper quadrant pain, palpable tender hepatomegaly, and elevated serum alkaline phosphatase.
Diagnosis is often pursued based on a prior episode of documented candidemia. Other organs that are affected include the spleen and kidneys. ${ }^{69}$ In a prospective study, 2019 episodes of candidemia were identified. ${ }^{21}$ Distribution of the organs involved in those determined to have disseminated disease were abdomen in 95 (53\%), lungs in 17 (9.5\%), skin and soft tissue in $14(7.8 \%)$, eyes in nine $(5 \%)$, heart in seven $(3.9 \%)$, tracheobronchial tree in seven $(3.9 \%)$, skeleton in three $(1.7 \%)$, and central nervous system in two $(1.1 \%)$. Lung involvement is rare, but is manifested as innumerable nodules on imaging, usually in conjunction with dissemination to other sites, and is mostly asymptomatic. Skeletal involvement can manifest as vertebral osteomyelitis/ discitis, and commonly manifests with progressive back pain and a relative lack of constitutional symptoms. ${ }^{70}$ Central nervous system involvement can be in the form of meningitis or brain abscess.

\section{Invasive mold infections}

The most common clinical presentation of invasive mold infection is pneumonia, with Aspergillus species being the leading cause in patients with hematologic malignancy, hematopoietic cell transplantation (especially in association with graft versus host disease and corticosteroid therapy), and solid organ transplantation. The classic symptoms include fever, cough, pleuritic chest pain, and, at times, hemoptysis, ${ }^{61}$ and on examination there may be a pleural rub. All of these symptoms are rarely present simultaneously. Aspergillus tracheobronchitis is seen more frequently in lung transplant recipients. ${ }^{71}$ Non-Aspergillus septated mold infections (Scedosporium, Fusarium, and Acremonium species), and Zygomycetes may also present in a similar manner. Invasive sinusitis can manifest as headache/sinus pain, nasal stuffiness with or without discharge, fever, ptosis, proptosis, and cranial nerve deficits. Rapidly progressive disease may be suggestive of zygomycosis. The nasal examination may reveal a grayish discoloration of the mucosa early on, and necrotic turbinates or eschar later on. Intracranial extension of invasive sinusitis can result in central nervous system infection, manifesting as brain abscess, cavernous sinus thrombosis, and meningitis. Central nervous system infection may result from hematogenous dissemination with vascular thrombosis and infarction. ${ }^{72}$ The angioinvasive molds have a propensity to cause brain abscesses. ${ }^{73}$ The sudden appearance of mental status changes and/or focal neurologic deficits should alert one to central nervous system involvement. Other manifestations include skin lesions in the setting of disseminated infection (such as Fusarium 
species, Acremonium species, Aspergillus species, and Zygomycetes), ocular involvement (endophthalmitis with blindness), osteoarticular infections, and uncommonly, gastrointestinal involvement.

\section{Diagnosis}

The diagnosis of invasive fungal infections can be challenging, especially when associated with protean manifestations. The European Organization for Research and Treatment of Cancer/Mycoses Study Group ${ }^{74}$ diagnostic criteria are used primarily for research purposes, but can be applied in clinical practice. Currently, diagnosis relies upon the presence of risk factors (host characteristics, ie, underlying disease, immunosuppressive regimen, and transplantation), microbiology, serologic testing (AGM and $\beta$-1,3-D-glucan assay [BDG]), and imaging. The gold standard for establishing proven infection is to obtain tissue for histologic or cultural confirmation of invasive disease.

\section{Candidemia/visceral candidiasis}

Culturing of blood is readily available but lacks sensitivity (ranging between 50\% and 70\%), which may be enhanced by cell centrifugation. For visceral candidiasis, a high index of clinical suspicion should lead to a diagnostic workup that would include imaging. The yield of a positive blood culture is poor in visceral invasive candidiasis, with candidemia detected in only $20 \%-30 \%$ of cases. ${ }^{70,75}$ Imaging (computed axial tomography [CT], ultrasonography, and magnetic resonance imaging [MRI] $)^{76}$ can be suggestive of this condition (hypodense lesions in liver, spleen, kidneys, and lungs). The pattern of radiographic abnormality suggesting different stages of infection has been described with ultrasonography, CT, and MRI. ${ }^{77}$ MRI may be more sensitive than CT for detection of lesions and staging of disease. ${ }^{76}$ Biopsy of the suspected lesion should be attempted, if feasible, for a definitive diagnosis, although sampling error is possible. BDG is an adjunctive test that can be useful, with sensitivity and specificity reported at $>90 \%$ in invasive candidiasis. ${ }^{78,79}$ It can also be positive in a number of other invasive fungal infections (such as aspergillosis and fusariosis). Another issue with BDG is the high rate of false positive results. Various other antibodies and antigens, along with polymerase chain reaction, have been studied but have not been approved for clinical use.

\section{Invasive mold infections}

The diagnosis of invasive mold infection can be problematic and is often delayed due to the presence of nonspecific symptoms. CT scan of the chest is often the first diagnostic test, and should be performed promptly in those suspected to have pneumonia due to invasive mold infection. The radiographic appearance can be quite variable, from the solitary nodule with a halo sign to later consolidation (with or without cavitation, air crescent sign).$^{80,81}$ It can also present just with diffuse infiltrates. The findings in zygomycosis can be similar, with a propensity to invade through the chest wall or extension through fissures. Radiographic findings due to molds other than Aspergillus species and Zygomycetes tend to be similar. Therefore, the specific fungal species causing the infection cannot be determined by radiographic appearance, and there is a need for further evaluation. Bronchoscopy with lavage, serologic testing (AGM, BDG), CT-guided biopsy of infiltrate, and open lung biopsy should be considered in sequence.

CT scan of the paranasal sinuses and orbits should be considered in those presenting with sinonasal symptoms. Endoscopic sinonasal examination with biopsies for microbiologic and histologic examination should be performed as necessary without delay. In situations where central nervous system disease is suspected, CT or MRI of the brain should be obtained, in conjunction with an assessment of the sinuses. The finding of a focal lesion suggestive of abscess or disseminated fungal infection, warrants consideration of a biopsy if feasible, unless there is another site proven to be involved. Cerebrospinal fluid should be sampled (if there are no contraindications) for diagnostic microbiologic, cytologic, antigen, and nucleic acid testing for invasive fungal infection and other opportunistic organisms.

Mold fungemia with positive blood cultures is observed frequently with infection due to Fusarium, Acremonium, and Scedosporium species, but rarely, if ever, with Aspergillus species. Skin is often involved, with multiple painful necrotic lesions, with Fusarium and Acremonium species, ${ }^{82,83}$ while lesions with Scedosporium are usually painless.

Serologic tests have been an important development as an adjunct in the diagnosis of invasive fungal infections. AGM and BDG have been incorporated into the European Organization for Research and Treatment of Cancer/ Mycoses Study Group criteria for diagnosis of fungal infection. The AGM test has low sensitivity in the setting of antimold prophylaxis, ${ }^{84}$ rendering its utility in acute myelogenous leukemia/myelodysplastic syndrome and hematopoietic cell transplantation uncertain, and therefore cannot be used as a screening test for preemptive therapy. The application of AGM and BDG in the diagnosis of invasive aspergillosis was recently reviewed. ${ }^{85}$ Polymerase chain 
reaction for diagnosis of invasive mold infection appears promising, but due to lack of standardization/validation, remains investigational.

\section{Antifungal agents}

Systemic antifungal agents available for the treatment of invasive fungal infections include the polyenes, azoles, echinocandins, and flucytosine (Table 3 ). The polyene class includes amphotericin B products. ${ }^{86}$ Amphotericin B deoxycholate is the oldest, and with infusion-related side effects. Amphotericin B lipid complex, liposomal amphotericin B, and amphotericin B colloidal dispersion are lipid formulations developed in an attempt to decrease these side effects. However, the latter of these agents is used less frequently than the other formulations due to a higher rate of infusionrelated reactions than with amphotericin B deoxycholate. Nephrotoxicity is another common adverse effect associated with all amphotericin B products. Their spectrum of activity is broad, and includes Aspergillus species (A. terreus is resistant), Zygomycetes, Candida species, and endemic fungi. ${ }^{87-89}$

The azoles used most commonly as systemic therapy in invasive fungal infection include fluconazole, itraconazole, voriconazole, and posaconazole. All azoles have activity against yeast such as Candida species; however, fluconazole has no mold activity. ${ }^{90,91}$ The azoles with mold activity are active against Aspergillus species.
Voriconazole has no activity against Zygomycetes, while posaconazole does have activity against Zygomycetes. The most common adverse effects of azoles are raised hepatic enzymes, $\mathrm{QT}_{\mathrm{c}}$ prolongation, food-drug interactions, and interactions with concomitant drugs that are substrates for or alter cytochrome P450 isoenzymes. ${ }^{92}$ Additionally, visual disturbances may occur with voriconazole. Therapeutic drug monitoring of azoles (except for fluconazole, given its limited drug-drug interactions and predictable bioavailability) would be beneficial to ensure adequate serum levels. ${ }^{92-95}$

The echinocandins are the most recent antifungal class, and comprise caspofungin, micafungin, and anidulafungin. These agents have activity against yeasts, such as Candida species, and molds, such as Aspergillus species. ${ }^{96,97}$ However, activity against other molds, such as Zygomycetes, is lacking, and increased tolerance has been observed with C. parapsilosis and C. guillermondii. ${ }^{18,98}$ Echinocandins are well tolerated, with few side effects, and they lack renal toxicity. Echinocandins can be used in patients with hepatic impairment (with dose reduction, as for caspofungin).

Flucytosine is an antimetabolite with in vitro activity against a variety of fungi, most notably Candida and Cryptococcus species. ${ }^{99}$ It is not used as monotherapy because resistance develops readily. Its main use is in combination therapy with amphotericin B for invasive candidiasis and cryptococcosis.

Table 3 Antifungal agents: uses, pros, and cons

\begin{tabular}{|c|c|c|}
\hline Drug & Uses & Comments \\
\hline Polyenes & Salvage therapy and empiric use due to broad activity & $\begin{array}{l}\text { Nephrotoxicity and infusion reactions are the largest } \\
\text { drawbacks }\end{array}$ \\
\hline Fluconazole & $\begin{array}{l}\text { IC in stable patients or stepdown agents; prophylaxis } \\
\text { in HCT; no need to monitor blood levels }\end{array}$ & No mold activity \\
\hline Itraconazole & $\begin{array}{l}\text { May be used as stepdown therapy where other azoles } \\
\text { are unavailable or intolerant in IC or invasive } \\
\text { aspergillosis; should monitor blood levels }\end{array}$ & $\begin{array}{l}\text { Limited usefulness, other agents may be preferred: } \\
\text { variable oral absorption, food and } \mathrm{pH} \text {-dependent, side } \\
\text { effect profile (Gl, cardiac, hepatic) }\end{array}$ \\
\hline Voriconazole & $\begin{array}{l}\text { First-line therapy in invasive aspergillosis; IC in stable } \\
\text { patients or stepdown therapy }\end{array}$ & $\begin{array}{l}\text { IV formulation contraindicated in renal impairment } \\
\mathrm{CrCl} \leq 50 \mathrm{~mL} / \mathrm{min} \text {; side effect profile (rash, visual, hepatic, } \\
\text { cardiac); DDI; associated emergence of zygomycosis; need } \\
\text { to monitor blood levels }\end{array}$ \\
\hline Posaconazole & $\begin{array}{l}\text { Prophylaxis in HCT/HM; salvage therapy for IFI } \\
\text { (eg, zygomycosis) }\end{array}$ & $\begin{array}{l}\text { Absorption dependent on high fat meals; side effect profile } \\
\text { (hepatic, cardiac although least toxic of azoles after } \\
\text { fluconazole); oral formulation only; need to monitor } \\
\text { blood levels }\end{array}$ \\
\hline Echinocandins & $\begin{array}{l}\text { Primary indication for IC; micafungin for prophylaxis in } \\
\text { HCT; caspofungin for empiric therapy in febrile } \\
\text { neutropenia; salvage therapy for invasive aspergillosis; } \\
\text { potential addition for combination therapy; few side } \\
\text { effects or DDI }\end{array}$ & $\begin{array}{l}\text { Not for primary monotherapy in invasive aspergillosis } \\
\text { Breakthrough IFI have been seen }\end{array}$ \\
\hline Flucytosine & Used in combination with other antifungal agents in IC & Marrow toxic; only oral formulation available \\
\hline
\end{tabular}

Abbreviations: $\mathrm{CrCl}$, creatinine clearance; DDI, drug-drug interactions; GI, gastrointestinal; HCT, hematopoietic cell transplantation; $\mathrm{HM}$, hematologic malignancy; IA, invasive aspergillosis; IC, invasive candidiasis; IFI, invasive fungal infection. 


\section{Invasive aspergillosis}

Voriconazole has the best clinical activity against Aspergillus and Scedosporium species, and is considered first-line therapy for infections caused by these pathogens. ${ }^{16,91,100}$ Amphotericin B products can be used as second-line agents in patients who cannot tolerate or are failing voriconazole therapy, ${ }^{101}$ and echinocandins can be used as alternative or salvage therapy. ${ }^{100,102-104}$

\section{Invasive candidiasis}

In severe cases of invasive candidiasis, such as in critically ill patients, amphotericin B products can be used with or without flucytosine. ${ }^{105}$ Echinocandins are effective against invasive candidiasis and are first-line therapy. ${ }^{97,105}$ Fluconazole and voriconazole are good choices for invasive candidiasis or stepdown therapy in severe cases of invasive candidiasis or candidemia after treatment with an amphotericin B product or an echinocandin. ${ }^{105}$

\section{Zygomycosis and other mold infections}

Delay in the use of an amphotericin B product up front in zygomycosis has been associated with poor survival outcome. ${ }^{106}$ Thus, the polyenes should be used first-line in invasive fungal infections caused by zygomycosis or unknown molds, because they have the broadest spectrum of coverage. ${ }^{28}$ Among the azoles, posaconazole is the only azole having activity against Zygomycetes, and has proven efficacy as salvage therapy for zygomycosis. ${ }^{91,107-109}$

\section{Combination therapy}

Data for combination antifungal therapy varies depending on the invasive fungal infection involved. For invasive candidiasis, especially for infections that are deepseated or where penetration may be an issue, such as in the central nervous system or in endocarditis, an amphotericin B product in combination with flucytosine may be used. ${ }^{99,105}$ This combination allows for synergy, as well as better penetration into the central nervous system, synovial fluid, or valves. Other data suggest that combination of fluconazole and amphotericin B may be a useful alternative. ${ }^{110}$

For other invasive fungal infections, data come mainly from in vitro studies, animal models, retrospective reviews, and case reports. Combination therapy for invasive aspergillosis is more controversial. Many in vitro and in vivo studies vary in methodology, but do suggest synergistic or additive effects when an echinocandin is combined with an amphotericin B product or an azole. ${ }^{111-113}$ Combinations of amphotericin $\mathrm{B}$ and an azole can demonstrate antagonism and clinical failure if amphotericin B is given after itraconazole, ${ }^{114}$ but also indifferent effects when given concurrently. ${ }^{115,116}$ Combining three classes (voriconazole, caspofungin, and amphotericin B) has shown variable results, depending on drug concentrations. ${ }^{117,118}$ Randomized, controlled studies are lacking in the evaluation of combination therapy. However, there is a study currently underway evaluating the clinical efficacy of voriconazole versus voriconazole plus anidulafungin in invasive aspergillosis.

For zygomycosis, data for combination therapy has shown some promise when iron chelators, such as deferiprone and deferasirox, are used in combination with liposomal amphotericin B. ${ }^{119,120}$ On the other hand, caution must be exercised when using other iron chelators, such as deferoxamine, which has been shown to aggravate zygomycosis by making siderophore iron-feroxamine complexes available to the pathogen. ${ }^{121} \mathrm{~A}$ combination of posaconazole and amphotericin B has not demonstrated added benefit. ${ }^{120}$ Data on combination therapy for other invasive mold infections are even more limited.

\section{Surgical intervention}

In certain situations, surgery may be warranted in order to resect the infected focus in invasive mold infection, particularly areas where antifungals have limited penetration. These may include solitary pulmonary lesions, invasion of the chest wall, osteomyelitis, pericardial infection, endocarditis, or fungal balls, such as aspergillomas. ${ }^{100}$ Other situations where surgical intervention may be necessary include debridement of infected tissues as in rhinosinusitis, cerebral lesions, infected skin and soft tissue, or removal of prosthetic devices, and infected vascular catheters. ${ }^{100,105,122}$ The latter is particularly important for candidemia. Candida species form a biofilm around catheters, and thus prevent complete eradication by antifungal agents alone and are associated with higher mortality. ${ }^{123,124}$ Timing of catheter removal, ie, 24 hours versus 48 hours, did not demonstrate significant differences in outcome, but removal versus no removal did. ${ }^{124}$

\section{Approaches to management}

Different approaches have been described for management of invasive fungal infection and have been thoroughly reviewed in the literature, and therefore only a brief summary of these approaches is described here. ${ }^{125,126}$ These approaches include empiric, "preemptive", prophylactic, and pathogen-specific therapy. ${ }^{125,126}$

Empiric therapy is an early approach in patients with febrile neutropenia, which usually entails starting or adjusting antifun- 
gal therapy in high-risk patients with unexplained fevers that are persistent or recurrent after 4-7 days of antibiotics. ${ }^{127}$

The preemptive approach is also an early treatment as empiric therapy. Preemptive therapy has traditionally been applied towards viral infection (ie, cytomegalovirus) where treatment is started for evidence (such as polymerase chain reaction for viral load) of infection (or viremia) before disease onset. However, this is not practical for invasive fungal infection because there is no preemptive test available. That is, there is no diagnostic test that predicts infection ahead of disease. Hence, this approach would be better described as "empiric" or "presumptive". Instead, it is based on suspicion for an invasive fungal infection that is already established, particularly mold infection. ${ }^{125}$ Suspicion may include seropositivity for AGM and supportive radiographic findings for invasive fungal infection in high-risk patients, and thus antimold agents are started. ${ }^{128}$

Prophylaxis against invasive fungal infection in hematopoietic cell transplant recipients has been shown to improve outcomes, such as decreasing invasive fungal infection rates. ${ }^{5,10,129-131}$ In hematopoietic cell transplantation, only prophylaxis with fluconazole has shown a survival benefit. ${ }^{5,132}$ Other antifungals have been compared with fluconazole, but none have demonstrated an improved survival benefit over fluconazole in hematopoietic cell transplantation. ${ }^{129,131}$ However, a survival benefit was demonstrated for posaconazole prophylaxis in neutropenic patients undergoing chemotherapy for acute myelogenous leukemia or myelodysplastic syndrome. ${ }^{10}$

Finally, from a practical point of view, the identity of the specific pathogen is rarely known. Therefore, a directed empirical approach to therapy should be employed using all the currently available information. ${ }^{125}$ When invasive candidiasis is suspected, the choice of antifungal agent depends on the current clinical presentation of the patient, such as hemodynamic stability, prior antifungal exposure, and resistance patterns at a particular institution. One may choose an azole, echinocandin, or amphotericin B product \pm flucytosine depending on the likelihood of an azole-resistant or echinocandin-resistant isolate and the risk of not adequately covering the pathogen. For suspicion of invasive mold infection, similar consideration can also determine the choice of antifungal. Choice can depend on the clinical presentation of the patient and likely focus of infection based on symptoms and radiographic data, prior prophylactic therapy, serology, and microbiologic/cytologic/ histologic results. Most importantly, the choice of an antifungal agent will depend on whether one can exclude or confirm the diagnosis of zygomycosis.

\section{Future horizons}

\section{New drugs and formulations}

A number of new antifungal agents are examined each year. Most are studied in vitro or in animal models. However, none are in the immediate clinical pipeline. New echinocandins and azoles are being developed, such as enfumafungin and isavuconazole. ${ }^{133,134}$ There are also new antifungals with novel mechanisms of action. One example is E1210, a broad spectrum inhibitor of glycosylphosphatidylinositol biosynthesis. ${ }^{135}$ It was found to inhibit fungal growth and biofilm formation, suppress some virulence factors in C. albicans, and have in vitro activity against $A$. fumigatus. ${ }^{136}$ Another novel antifungal class includes FG3409, a small molecule antifungal with a proprietary "novel mechanism of action". It was found to reduce tissue burden in a murine model of disseminated invasive aspergillosis with greater potency than the azoles and amphotericin B in vitro. ${ }^{137}$ It also demonstrated greater potency than posaconazole or voriconazole against Scedosporium species, including S. prolificans, which is often resistant to current commercially available antifungals. ${ }^{138}$ Other novel classes include phosphoinositidedependent kinase 1 inhibitors which target the cell wall integrity signaling pathway, ${ }^{139}$ and others that synergize with azoles. These include histone deacetylase inhibitors, which modulate genes involved in cell wall integrity, ${ }^{140}$ and type II topoisomerase inhibitors. ${ }^{141}$ In addition to new classes of antifungals, novel drug delivery technology has been applied to conventional antifungals, such as itraconazole. A nanosuspension formulation demonstrated improved itraconazole activity and less toxicity by eliminating its cardiac inotropic effects. ${ }^{142}$ A new solid oral formulation of posaconazole with improved oral bioavailability over the current oral solution is currently under investigation.

\section{Immunotherapy and vaccines}

Despite the development of more active and less toxic antifungal agents, mortality rates for invasive fungal infection remain unacceptably high. There is a need for different approaches to both treatment and prevention. Recent efforts have focused on immunotherapy and vaccines. ${ }^{143}$

In general, the primary protective defense mechanism against invasive fungal infection is T cell-mediated immunity, specifically, a robust Th1 response to fungal antigens. ${ }^{144}$ In the immunocompromised host at risk of invasive fungal infection, $\mathrm{T}$ cell immunity is compromised due to a number of factors, including corticosteroid therapy. Cenci et al first demonstrated that passively transferred Aspergillusspecific Th1-committed CD4+ T cells could protect animals 
against invasive aspergillosis. ${ }^{145}$ Beck et al has shown that Aspergillus-specific CD4+ T cells can be identified and expanded ex vivo to adequate numbers for infusion into patients. ${ }^{146}$ Recently, Perruccio et al demonstrated use of Aspergillus-specific immunotherapy in hematopoietic cell transplantation that provided rapid immune recovery. ${ }^{147}$

Vaccination to prevent invasive fungal infection in the immunocompromised host is a relatively new concept. It was not even attempted because of the assumption that severely immunocompromised patients (eg, hematopoietic cell transplantation recipients) cannot be vaccinated effectively within a year after their transplant..$^{39,147}$ However, it was demonstrated in an animal model that a crude Aspergillus vaccine administered before immunosuppression (neutropenia or corticosteroid therapy) protected against subsequent invasive aspergillosis. ${ }^{145,148}$ Efforts are now focused on identifying epitope(s) with $\mathrm{T}$ cell immunogenic and protective properties. Also, work on adjuvants ${ }^{149}$ and dendritic cell vaccination ${ }^{150}$ have demonstrated promising results. Finally, there have been efforts toward developing Candida vaccines, and these has been thoroughly reviewed recently. ${ }^{151}$

\section{Conclusion}

Over the past 20 years, the number of invasive fungal infections has continued to persist, due primarily to the increased numbers of patients we subject to severe immunosuppression. Despite the development of more active and less toxic antifungal agents and the standard use of antifungal prophylaxis, invasive fungal infection (especially invasive mold infection) continues to be a significant factor in hematopoietic cell and solid organ transplantation outcomes, resulting in high mortality rates. Since the advent of fluconazole as standard prophylaxis in the hematopoietic cell transplant setting, invasive candidiasis has come under control, but no mold-active antifungal agent (except for posaconazole in the acute myelogenous leukemia/myelodysplastic syndrome setting) has been shown to improve on the survival rate over fluconazole. With the introduction of new azole and echinocandin agents, we have seen the emergence of more azole-resistant and echinocandin-resistant fungi. The recent increase in zygomycosis seen in the hematopoietic cell transplant setting may be due to the increased use of voriconazole. This has implications for the empiric approach to pulmonary invasive mold infection when zygomycosis cannot be ruled out. It is imperative that an amphotericin B product, an antifungal that in over 50 years has never developed resistance, be initiated.

The clinical presentations of invasive mold infection and invasive candidiasis can be nonspecific and the diagnostic tests insensitive, so a high index of suspicion and immediate initiation of empiric therapy is required. Unfortunately, our currently available serologic tests do not predict infection ahead of disease, and, therefore, cannot be used to initiate "preemptive" therapy. Furthermore, the AGM test gives a false negative result in patients receiving antimold prophylaxis, ie, virtually all of our patients with hematologic malignancy and hematopoietic cell transplant recipients. We may eventually be able to select patients at highest risk for invasive fungal infections for prophylaxis by genetic testing. However, with our current armamentarium of antifungal agents and widespread use of prophylaxis in high-risk groups (hematologic malignancy, hematopoietic cell transplantation), we continue to see high incidence and mortality rates, and our future hope lies in reversing immunosuppression or augmenting the immune system in these severely immunocompromised hosts by developing and utilizing immunotherapy, immunoprophylaxis, and vaccines.

\section{Disclosure}

JII reports participating on speaker's bureaus for Astellas, Merck, and Pfizer, and consulting for Sigma Tau. JK and SSD have no potential conflict of interest to report.

\section{References}

1. Baddley JW, Andes DR, Marr KA, et al. Factors associated with mortality in transplant patients with invasive aspergillosis. Clin Infect Dis. 2010; 50(12):1559-1567.

2. Kontoyiannis DP, Marr KA, Park BJ, et al. Prospective surveillance for invasive fungal infections in hematopoietic stem cell transplant recipients, 2001-2006: Overview of the Transplant-Associated Infection Surveillance Network (TRANSNET) Database. Clin Infect Dis. 2010;50(8):1091-1100.

3. Park BJ, Pappas PG, Marr KA, et al. Recent epidemiology of zygomycosis among organ transplant and stem cell transplant recipients: Results from the TRANSNET surveillance network. Abstract M-618 presented at the 47th Interscience Conference on Antimicrobial Agents and Chemotherapy, Chicago, IL, September 17-20, 2007.

4. Pappas PG, Alexander BD, Andes DR, et al. Invasive fungal infections among organ transplant recipients: Results of the Transplant-Associated Infection Surveillance Network (TRANSNET). Clin Infect Dis. 2010; 50(8):1101-1111.

5. Slavin MA, Osborne B, Adams R, et al. Efficacy and safety of fluconazole prophylaxis for fungal infections after marrow transplantation a prospective, randomized, double-blind study. J Infect Dis. 1995; 171(6): $1545-1552$.

6. Tomblyn M, Chiller T, Einsele H, et al. Guidelines for preventing infectious complications among hematopoietic cell transplantation recipients: A global perspective. Biol Blood Marrow Transplant. 2009;15(10):1143-1238.

7. Marr KA, Carter RA, Crippa F, Wald A, Corey L. Epidemiology and outcome of mould infections in hematopoietic stem cell transplant recipients. Clin Infect Dis. 2002;34(7):909-917.

8. Brayman KL, Stephanian E, Matas AJ, et al. Analysis of infectious complications occurring after solid-organ transplantation. Arch Surg. 1992;127(1):38-47.

9. Paya CV. Fungal infections in solid-organ transplantation. Clin Infect Dis. 1993;16(5):677-688. 
10. Cornely OA, Maertens J, Winston DJ, et al. Posaconazole vs fluconazole or intraconazole prophylaxis in patients with neutropenia. $N$ Engl J Med. 2007;356(4):348-359.

11. Mattiuzzi GN, Kantarjian H, Faderl S, et al. Amphotericin B lipid complex as prophylaxis of invasive fungal infections in patients with acute myelogenous leukemia and myelodysplastic syndrome undergoing induction chemotherapy. Cancer. 2004;100(3):581-589.

12. Vreugdenhil G, Van Dijke BJ, Donnelly JP, et al. Efficacy of itraconazole in the prevention of fungal infections among neutropenic patients with hematologic malignancies and intensive chemotherapy. A double blind, placebo controlled study. Leuk Lymphoma. 1993;11(5-6): 353-358.

13. Menichetti F, Del Favero A, Martino P, et al. Itraconazole oral solution as prophylaxis for fungal infections in neutropenic patients with hematologic malignancies: A randomized, placebo-controlled, double-blind, multicenter trial. GIMEMA Infection Program. Gruppo Italiano Malattie Ematologiche dell' Adulto. Clin Infect Dis. 1999; 28(2):250-255.

14. Lehrnbecher T, Frank C, Engels K, Kriener S, Groll AH, Schwabe D. Trends in the postmortem epidemiology of invasive fungal infections at a university hospital. J Infect. 2010;61(3):259-265.

15. Vincent JL, Rello J, Marshall J, et al. International study of the prevalence and outcomes of infection in intensive care units. JAMA. 2009;302(21):2323-2329.

16. Herbrecht R, Denning DW, Patterson TF, Bennett JE, Greene RE. Voriconazole versus amphotericin B for primary therapy of invasive aspergillosis. N Engl J Med. 2002;347(6):408-415.

17. Steinbach WJ, Benjamin DK Jr, Kontoyiannis DP, et al. Infections due to Aspergillus terreus: A multicenter retrospective analysis of 83 cases. Clin Infect Dis. 2004;39(2):192-198.

18. Pfeiffer CD, Garcia-Effron G, Zaas AK, Perfect JR, Perlin DS, Alexander BD. Breakthrough invasive candidiasis in patients on micafungin. J Clin Microbiol. 2010;48(7):2373-2380.

19. Vazquez JA. Invasive fungal infections in the intensive care unit. Semin Respir Crit Care Med. 2010;31(1):79-86.

20. Arendrup MC. Epidemiology of invasive candidiasis. Curr Opin Crit Care. 2010;16(5):445-452.

21. Horn DL, Neofytos D, Anaissie EJ, et al. Epidemiology and outcomes of candidemia in 2019 patients: Data from the prospective antifungal therapy alliance registry. Clin Infect Dis. 2009;48(12):1695-1703.

22. Hidron AI, Edwards JR, Patel J, et al. NHSN annual update: Antimicrobial-resistant pathogens associated with healthcare-associated infections: Annual summary of data reported to the National Healthcare Safety Network at the Centers for Disease Control and Prevention, 2006-2007. Infect Control Hosp Epidemiol. 2008;29(11): 996-1011.

23. Neumann PR, Rakower SR. The risk of positive cultures for Candida in the critically ill patient. Crit Care Med. 1978;6(2):73-76.

24. Kett DH, Azoulay E, Echeverria PM, Vincent JL. Candida bloodstream infections in intensive care units: Analysis of the extended prevalence of infection in a intensive care unit study. Crit Care Med. December 16, 2010. [Epub ahead of print].

25. Neofytos D, Horn D, Anaissie E, et al. Epidemiology and outcome of invasive fungal infection in adult hematopoietic stem cell transplant recipients: Analysis of Multicenter Prospective Antifungal Therapy (PATH) Alliance registry. Clin Infect Dis. 2009;48(3):265-273.

26. Ambrosioni J, Bouchuiguir-Wafa K, Garbino J. Emerging invasive zygomycosis in a tertiary care center: Epidemiology and associated risk factors. Int J Infect Dis. 2010;14 Suppl 3:e100-e103.

27. Trifilio S, Singhal S, Williams S, et al. Breakthrough fungal infections after allogeneic hematopoietic stem cell transplantation in patients on prophylactic voriconazole. Bone Marrow Transplant. 2007;40(5):451-456.

28. Trifilio SM, Bennett CL, Yarnold PR, et al. Breakthrough zygomycosis after voriconazole administration among patients with hematologic malignancies who receive hematopoietic stem-cell transplants or intensive chemotherapy. Bone Marrow Transplant. 2007;39(7):425-429.
29. Suzuki K, Sugawara Y, Sekine T, Nakase K, Katayama N. Breakthrough disseminated zygomycosis induced massive gastrointestinal bleeding in a patient with acute myeloid leukemia receiving micafungin. $J$ Infect Chemother. 2009;15(1):42-45.

30. Espinel-Ingroff A. Mechanisms of resistance to antifungal agents: Yeasts and filamentous fungi. Rev Iberoam Micol. 2008;25(2):101-106. Spanish.

31. Chapeland-Leclerc F, Hennequin C, Papon N, et al. Acquisition of flucytosine, azole, and caspofungin resistance in Candida glabrata bloodstream isolates serially obtained from a hematopoietic stem cell transplant recipient. Antimicrob Agents Chemother. 2010;54(3):1360-1362.

32. Law D, Moore CB, Wardle HM, Ganguli LA, Keaney MG, Denning DW. High prevalence of antifungal resistance in Candida spp. from patients with acquired immunodeficiency syndrome. J Antimicrob Chemother. 1994;34(5):659-668.

33. Westbrook SD, Wiederhold NP, Vallor AC, et al. Loss of in vitro resistance in Candida glabrata following discontinuation of fluconazole prophylaxis in a hematopoietic stem cell transplantation patient. Med Mycol. 2010;48(3):557-560.

34. Laverdière M, Lalonde RG, Baril JG, Sheppard DC, Park S, Perlin DS. Progressive loss of echinocandin activity following prolonged use for treatment of Candida albicans oesophagitis. J Antimicrob Chemother. 2006;57(4):705-708.

35. Mellado E, Garcia-Effron G, Alcazar-Fuoli L, et al. A new Aspergillus fumigatus resistance mechanism conferring in vitro cross-resistance to azole antifungals involves a combination of cyp51A alterations. Antimicrob Agents Chemother. 2007;51(6):1897-1904.

36. Rajendran R, Mowat E, McCulloch E, et al. Azole resistance of Aspergillus fumigatus biofilms is partly associated with efflux pump activity. Antimicrob Agents Chemother. February 14, 2011. [Epub ahead of print].

37. Howard SJ, Cerar D, Anderson MJ, et al. Frequency and evolution of azole resistance in Aspergillus fumigatus associated with treatment failure. Emerg Infect Dis. 2009;15(7):1068-1076.

38. Schelenz S, Abdallah S, Gray G, et al. Epidemiology of oral yeast colonization and infection in patients with hematological malignancies, head neck and solid tumors. J Oral Pathol Med. 2011;40(1):83-89.

39. Storek J, Dawson MA, Lim LC, et al. Efficacy of donor vaccination before hematopoietic cell transplantation and recipient vaccination both before and early after transplantation. Bone Marrow Transplant. 2004;33(3):337-346.

40. Fishman JA, Issa NC. Infection in organ transplantation: Risk factors and evolving patterns of infection. Infect Dis Clin North Am. 2010; 24(2):273-283.

41. Egerer G, Geist MJ. Posaconazole prophylaxis in patients with acute myelogenous leukaemia - results from an observational study. Mycoses. 2011;54 Suppl 1:7-11.

42. Orasch C, Weisser M, Mertz D, et al. Comparison of infectious complications during induction/consolidation chemotherapy versus allogeneic hematopoietic stem cell transplantation. Bone Marrow Transplant. 2010;45(3):521-526.

43. Bodey GP. Infectious complications of acute leukemia. Med Times. 1966;94(9):1076-1085.

44. Pagano L, Akova M, Dimopoulos G, Herbrecht R, Drgona L, Blijlevens N. Risk assessment and prognostic factors for mould-related diseases in immunocompromised patients. J Antimicrob Chemother. 2011;66 Suppl 1:5-14.

45. Portugal RD, Garnica M, Nucci M. Index to predict invasive mold infection in high-risk neutropenic patients based on the area over the neutrophil curve. J Clin Oncol. 2009;27(23):3849-3854.

46. Wald A, Leisenring W, van Burik JA, Bowden RA. Epidemiology of Aspergillus infections in a large cohort of patients undergoing bone marrow transplantation. J Infect Dis. 1997;175(6):1459-1466.

47. Jantunen E, Ruutu P, Niskanen L, et al. Incidence and risk factors for invasive fungal infections in allogeneic BMT recipients. Bone Marrow Transplant. 1997;19(8):801-808. 
48. Van Burik JA, Carter SL, Freifeld AG, et al. Higher risk of cytomegalovirus and aspergillus infections in recipients of $\mathrm{T}$ celldepleted unrelated bone marrow: Analysis of infectious complications in patients treated with $T$ cell depletion versus immunosuppressive therapy to prevent graft-versus-host disease. Biol Blood Marrow Transplant. 2007;13(12):1487-1498

49. De La Rosa GR, Champlin RE, Kontoyiannis DP. Risk factors for the development of invasive fungal infections in allogeneic blood and marrow transplant recipients. Transpl Infect Dis. 2002 4(1):3-9.

50. Schmeiser T, Wiesneth M, Bunjes D, et al. Infectious complications after allogeneic bone marrow transplantation with and without T-cell depletion of donor marrow. Infection. 1989;17(3):124-130.

51. Pirsch JD, Maki DG. Infectious complications in adults with bone marrow transplantation and T-cell depletion of donor marrow. Increased susceptibility to fungal infections. Ann Intern Med. 1986; 104(5):619-631.

52. Thursky K, Byrnes G, Grigg A, Szer J, Slavin M. Risk factors for post-engraftment invasive aspergillosis in allogeneic stem cell transplantation. Bone Marrow Transplant. 2004;34(2):115-121.

53. Labbe $\mathrm{AC}, \mathrm{Su} \mathrm{SH}$, Laverdiere $\mathrm{M}$, et al. High incidence of invasive aspergillosis associated with intestinal graft-versus-host disease following nonmyeloablative transplantation. Biol Blood Marrow Transplant 2007;13(10):1192-1200.

54. Alderson JW, Van Dinter TG Jr, Opatowsky MJ, Burton EC. Disseminated aspergillosis following infliximab therapy in an immunosuppressed patient with Crohn's disease and chronic hepatitis C: A case study and review of the literature. Med Gen Med. 2005;7(3):7.

55. Bochud PY, Chien JW, Marr KA, et al. Toll-like receptor 4 polymorphisms and aspergillosis in stem-cell transplantation. $N$ Engl J Med. 2008;359(17):1766-1777.

56. Sainz J, Salas-Alvarado I, Lopez-Fernandez E, et al. TNFR1 mRNA expression level and TNFR1 gene polymorphisms are predictive markers for susceptibility to develop invasive pulmonary aspergillosis. Int J Immunopathol Pharmacol. 2010;23(2):423-436.

57. Carvalho A, Cunha C, Carotti A, et al. Polymorphisms in Toll-like receptor genes and susceptibility to infections in allogeneic stem cell transplantation. Exp Hematol. 2009;37(9):1022-1029.

58. Seo KW, Kim DH, Sohn SK, et al. Protective role of interleukin-10 promoter gene polymorphism in the pathogenesis of invasive pulmonary aspergillosis after allogeneic stem cell transplantation. Bone Marrow Transplant. 2005;36(12):1089-1095.

59. Panackal AA, Li H, Kontoyiannis DP, et al. Geoclimatic influences on invasive aspergillosis after hematopoietic stem cell transplantation. Clin Infect Dis. 2010;50(12):1588-1597.

60. Blumberg HM, Jarvis WR, Soucie JM, et al. Risk factors for candidal bloodstream infections in surgical intensive care unit patients: The NEMIS prospective multicenter study. The National Epidemiology of Mycosis Survey. Clin Infect Dis. 2001;33(2):177-186.

61. Segal BH. Aspergillosis. N Engl J Med. 2009;360(18):1870-1884.

62. Bodey G, Bueltmann B, Duguid W, et al. Fungal infections in cancer patients: An international autopsy survey. Eur J Clin Microbiol Infect Dis. 1992;11(2):99-109.

63. Sickles EA, Greene WH, Wiernik PH. Clinical presentation of infection in granulocytopenic patients. Arch Intern Med. 1975;135(5): 715-719.

64. Viscoli C, Girmenia C, Marinus A, et al. Candidemia in cancer patients: A prospective, multicenter surveillance study by the Invasive Fungal Infection Group (IFIG) of the European Organization for Research and Treatment of Cancer (EORTC). Clin Infect Dis. 1999;28(5): 1071-1079.

65. Pagano L, Antinori A, Ammassari A, et al. Retrospective study of candidemia in patients with hematological malignancies. Clinical features, risk factors and outcome of 76 episodes. Eur J Haematol. 1999;63(2):77-85.

66. Fine JD, Miller JA, Harrist TJ, Haynes HA. Cutaneous lesions in disseminated candidiasis mimicking ecthyma gangrenosum. Am J Med. 1981;70(5):1133-1135.
67. Kanski J, Pavesio C, Tuft S. Endophthalmitis. In: Ocular Inflammatory Disease. Philadelphia, PA: Elsevier; 2006.

68. Rabinovici R, Szewczyk D, Ovadia P, Greenspan JR, Sivalingam JJ. Candida pericarditis: Clinical profile and treatment. Ann Thorac Surg. 1997;63(4):1200-1204.

69. Pagano L, Mele L, Fianchi L, et al. Chronic disseminated candidiasis in patients with hematologic malignancies. Clinical features and outcome of 29 episodes. Haematologica. 2002;87(5): 535-541.

70. Miller DJ, Mejicano GC. Vertebral osteomyelitis due to Candida species: Case report and literature review. Clin Infect Dis. 2001;33(4): 523-530.

71. Singh N, Husain S. Aspergillus infections after lung transplantation: Clinical differences in type of transplant and implications for management. J Heart Lung Transplant. 2003;22(3):258-266.

72. Kleinschmidt-DeMasters BK. Central nervous system aspergillosis: A 20-year retrospective series. Hum Pathol. 2002;33(1):116-124.

73. Walsh TJ, Hier DB, Caplan LR. Fungal infections of the central nervous system: comparative analysis of risk factors and clinical signs in 57 patients. Neurology. 1985;35(11):1654-1657.

74. De Pauw B, Walsh TJ, Donnelly JP, et al. Revised Definitions of Invasive Fungal Disease from the European Organization for Research and Treatment of Cancer/Invasive Fungal Infections Cooperative Group and the National Institute of Allergy and Infectious Diseases Mycoses Study Group (EORTC/MSG) Consensus Group. Clin Infect Dis. 2008;46(12):1813-1821.

75. Anaissie E, Bodey GP, Kantarjian H, et al. Fluconazole therapy for chronic disseminated candidiasis in patients with leukemia and prior amphotericin B therapy. Am J Med. 1991;91(2):142-150.

76. Samuels BI, Pagani JJ, Libshitz HI. Radiographic features of candida infections. In: Bodey GP, editor. Candidiasis: Pathogenesis, Diagnosis and Treatments. New York, NY: Raven Press; 1993.

77. Semelka RC, Shoenut JP, Greenberg HM, Bow EJ. Detection of acute and treated lesions of hepatosplenic candidiasis: Comparison of dynamic contrast-enhanced CT and MR imaging. J Magn Reson Imaging. 1992;2(3):341-345.

78. Semelka RC, Kelekis NL, Sallah S, Worawattanakul S, Ascher SM. Hepatosplenic fungal disease: Diagnostic accuracy and spectrum of appearances on MR imaging. AJR Am J Roentgenol. 1997;169(5): 1311-1316.

79. Ostrosky-Zeichner L, Alexander BD, Kett DH, et al. Multicenter clinical evaluation of the $(1 \geq 3)$ beta-D-glucan assay as an aid to diagnosis of fungal infections in humans. Clin Infect Dis. 2005;41(5):654-659.

80. Logan PM, Primack SL, Miller RR, Muller NL. Invasive aspergillosis of the airways: Radiographic, CT, and pathologic findings. Radiology. 1994;193(2):383-388.

81. Kuhlman JE, Fishman EK, Siegelman SS. Invasive pulmonary aspergillosis in acute leukemia: Characteristic findings on CT, the CT halo sign, and the role of CT in early diagnosis. Radiology. 1985;157(3): 611-614.

82. Nucci M, Anaissie E. Cutaneous infection by Fusarium species in healthy and immunocompromised hosts: Implications for diagnosis and management. Clin Infect Dis. 2002;35(8):909-920.

83. Krcmery V Jr, Kunova E, Jesenska Z, et al. Invasive mold infections in cancer patients: 5 years' experience with Aspergillus, Mucor, Fusarium and Acremonium infections. Support Care Cancer. 1996;4(1):39-45.

84. Marr KA, Laverdiere M, Gugel A, Leisenring W. Antifungal therapy decreases sensitivity of the Aspergillus galactomannan enzyme immunoassay. Clin Infect Dis. 2005;40(12):1762-1769.

85. Wheat LJ. Approach to the diagnosis of invasive aspergillosis and candidiasis. Clin Chest Med. 2009;30(2):367-377, viii.

86. Wong-Beringer A, Jacobs RA, Guglielmo BJ. Lipid formulations of amphotericin B: Clinical efficacy and toxicities. Clin Infect Dis. 1998;27(3):603-618.

87. Messer SA, Moet GJ, Kirby JT, Jones RN. Activity of contemporary antifungal agents, including the novel echinocandin anidulafungin, tested against Candida spp., Cryptococcus spp., and Aspergillus spp.: Report from the SENTRY Antimicrobial Surveillance Program (2006 to 2007). J Clin Microbiol. 2009;47(6):1942-1946. 
88. Dannaoui E, Meletiadis J, Mouton JW, Meis JF, Verweij PE. Eurofung Network. In vitro susceptibilities of zygomycetes to conventional and new antifungals. $J$ Infect Dis. 2003;51(1):45-52.

89. Baddley JW, Marr KA, Andes DR, et al. Patterns of susceptibility of Aspergillus isolates recovered from patients enrolled in the TransplantAssociated Infection Surveillance Network. J Clin Microbiol. 2009; 47(10):3271-3275.

90. Pfaller MA, Zhang J, Messer SA, et al. In vitro activities of voriconazole, fluconazole, and itraconazole against 566 clinical isolates of Cryptococcus neoformans from the United States and Africa. Antimicrob Agents Chemother. 1999;43(1):169-170.

91. Diekema D, Messer SA, Hollis RJ, Jones RN, Pfaller MA. Activities of caspofungin, itraconazole, posaconazole, ravuconazole, voricaonzole, and amphotericin B against 448 recent clinical isolates of filamentous fungi. J Clin Microbiol. 2003;41(8):3623-3626.

92. Dodds Ashley ES, Lewis R, Lewis JS, Marin C, Andes D. Pharmacology of systemic antifungal agents. Clin Infect Dis. 2006; 43 Suppl:S28-S39.

93. Trifilio S, Ortiz R, Pennick G, et al. Voriconazole therapeutic drug monitoring in allogeneic hematopoietic stem cell transplant recipients. Bone Marrow Transplant. 2005;35(5):509-513.

94. Summers KK, Hardin TC, Gore SJ, Graybill JR. Therapeutic drug monitoring of systemic antifungal therapy. J Antimicrob Chemother. 1997;40(6):753-764.

95. Pascual A, Calandra T, Bolay S, Buclin T, Bille J, Marchetti O. Voriconazole therapeutic drug monitoring in patients with invasive mycoses improves efficacy and safety outcomes. Clin Infect Dis. 2008;46(2):201-211.

96. Mora-Duarte J, Betts R, Rotstein C, et al. Comparison of caspofungin and amphotericin B for invasive candidiasis. $N$ Engl J Med. 2002;347(25):2020-2029.

97. Pappas PG, Rotstein CM, Betts RF, et al. Micafungin versus caspofungin for treatment of candidemia and other forms of invasive candidiasis. Clin Infect Dis. 2007;45(7):883-893.

98. Moore CB, Denning DW. Tolerance and fungicidality in vitro of caspofungin, micafungin and anidulafungin against Candida guilliermondii. Abstract M-230 presented at the 42nd Annual Interscience Conference on Antimicrobial Agents and Chemotherapy, September 27-30, 2002, San Diego, CA.

99. Thompson GR 3rd, Cadena J, Patterson TF. Overview of antifungal agents. Clin Chest Med. 2009;30(2):203-215, v.

100. Walsh TJ, Anaissie EJ, Denning DW, et al. Treatment of aspergillosis: Clinical practice guidelines of the Infectious Diseases Society of America. Clin Infect Dis. 2008;46(3):27-60.

101. Walsh TJ, Raad I, Patterson TF, et al. Treatment of invasive aspergillosis with posaconazole in patients who are refractory to or intolerant of conventional therapy: An externally controlled trial. Clin Infect Dis. 2007;44(1):2-12.

102. Denning DW, Marr KA, Lau WM, et al. Micafungin (FK463), alone or in combination with other systemic antifungal agents, for the treatment of acute invasive aspergillosis. J Infect. 2006;53(5):337-349.

103. Betts R, Glasmacher A, Maertens J, et al. Efficacy of caspofungin against invasive Candida or invasive Aspergillus infections in neutropenic patients. Cancer. 2006;106(2):466-473.

104. Maertens J, Raad I, Petrikkos G, et al. Efficacy and safety of caspofungin for treatment of invasive aspergillosis in patients refractory to or intolerant of conventional antifungal therapy. Clin Infect Dis. 2004;39(11):1563-1571.

105. Pappas PG, Kauffman CA, Andes D, et al. Clinical practice guidelines for the management of candidiasis: 2009 update by the Infectious Diseases Society of America. Clin Infect Dis. 2009;48(5):503-535.

106. Chamilos G, Lewis RE, Kontoyiannis DP. Delaying amphotericin B-based frontline therapy significantly increases mortality among patients with hematologic malignancy who have zygomycosis. Clin Infect Dis. 2008;47(4):503-509.
107. Manavathu EK, Cutright JL, Chandrasekar PH. Organism-dependent fungicidal activities of azoles. Antimicrob Agents Chemother. 1998;42(11):3018-3021.

108. Lass-Florl C, Mayr A, Perkhofer S, et al. Activities of antifungal agents against yeasts and filamentous fungi: Assessment according to the Methodology of the European Committee on Antimicrobial Susceptibility Testing. Antimicrob Agents Chemother. 2008;52(10):3637-3641.

109. Van Burik JA, Hare RS, Solomon HF, Corrado ML, Kontoyiannis DP. Posaconazole is effective as salvage therapy in zygomycosis: A retrospective summary of 91 cases. Clin Infect Dis. 2006;42(7):e61-e65.

110. Rex JH, Pappas PG, Karchmer AW, et al. A randomized and blinded multicenter trial of high-dose fluconazole plus placebo versus fluconazole plus amphotericin B as therapy for candidemia and its consequences in nonneutropenic subjects. Clin Infect Dis. 2003;36(10):1221-1228.

111. Marr KA, Boeckh M, Carter RA, Kim HW, Corey L. Combination antifungal therapy for invasive aspergillosis. Clin Infect Dis. 2004; 39(6):797-802.

112. Caillot D, Thiebaut A, Herbrecht R, et al. Liposomal amphotericin B in combination with caspofungin for invasive aspergillosis in patients with hematologic malignancies: A randomized pilot study (Combistrat trial). Cancer. 2007;110(12):2740-2746.

113. Cuenca-Estrella M, Gomez-Lopez A, Garcia-Effron G, et al. Combined activity in vitro of caspofungin, amphotericin B, and azole agents against itraconazole-resistant clinical isolates of Aspergillus fumigatus. Antimicrob Agents Chemother. 2005;49(3):1232-1235.

114. Schaffner A, Annette B. Amphotericin B refractory aspergillosis after itraconazole: Evidence for significant antagonism. Mycoses. 1993;36(11-12):421-424.

115. Popp AI, White MH, Quadri T, Walshe L, Armstrong D. Amphotericin $B$ with and without itraconazole for invasive aspergillosis: A three-year retrospective study. Int J Infect Dis. 1999;3(3):157-160.

116. Chandrasekar PH, Cutright JL, Manavathu EK. Efficacy of voriconazole plus amphotericin B or micafungin in a guinea-pig model of invasive pulmonary aspergillosis. Clin Microbiol Infect. 2004;10(10):925-928.

117. O'Shaughnessy EM, Meletiadis J, Stergiopoulou T, Demchok JP, Walsh TJ. Antifungal interactions within the triple combination of amphotericin B, caspofungin and voriconazole against Aspergillus species. J Antimicrob Chemother. 2006;58(6):1168-1176.

118. Meletiadis J, Stergiopoulou T, O’Shaughnessy EM, Peter J, Walsh TJ. Concentration-dependent synergy and antagonism within a triple antifungal drug combination against Aspergillus species: Analysis by a new response surface model. Antimicrob Agents Chemother. 2007;51(6):2053-2064.

119. Ibrahim AS, Edwards JE Jr, Fu Y, Spellberg B. Deferiprone iron chelation as a novel therapy for experimental mucormycosis. J Antimicrob Chemother. 2006;58(5):1070-1073.

120. Spellberg B, Walsh TJ, Kontoyiannis DP, Edwards J Jr, Ibrahim AS. Recent advances in the management of mucormycosis: From bench to bedside. Clin Infect Dis. 2009;48(12):1743-1751.

121. Boelaert JR, de Locht M, Van Cutsem J, et al. Mucormycosis during deferoxamine therapy is a siderophore-mediated infection. In vitro and in vivo animal studies. J Clin Invest. 1993;91(5):1979-1986.

122. Kasapoglu F, Coskun H, Ozmen OA, Akalin H, Ener B. Acute invasive fungal rhinosinusitis: Evaluation of 26 patients treated with endonasal or open surgical procedures. Otolaryngol Head Neck Surg. 2010;143(5):614-620.

123. Tumbarello M, Posteraro B, Trecarichi EM, et al. Biofilm production by Candida species and inadequate antifungal therapy as predictors of mortality for patients with candidemia. J Clin Microbiol. 2007;45(6):1843-1850.

124. Nucci M, Anaissie E, Betts RF, et al. Early removal of central venous catheter in patients with candidemia does not improve outcome: Analysis of 842 patients from 2 randomized clinical trials. Clin Infect Dis. 2010;51(3):295-303. 
125. Ito JI, Kriengkauykiat J, Dadwal SS, Arfons LM, Lazarus HM. Approaches to the early treatment of invasive fungal infection. Leuk Lymphoma. 2010;51(9):1623-1631.

126. Michallet M, Ito JI. Approaches to the management of invasive fungal infections in hematologic malignancy and hematopoietic cell transplantation. J Clin Oncol. 2009;27(20):3398-3409.

127. Freifeld AG, Bow EJ, Sepkowitz KA, et al. Clinical practice guideline for the use of antimicrobial agents in neutropenic patients with cancer: 2010 update by the Infectious Diseases Society of America. Clin Infect Dis. 2011;52(4):e56-e93.

128. Maertens J, Theunissen K, Lodewyck T, Lagrou K, Van Eldere J. Advances in the serological diagnosis of invasive Aspergillus infections in patients with haematological disorders. Mycoses. 2007; 50 Suppl 1:2-17.

129. Ullmann AJ, Lipton JH, Vesole DH, et al. Posaconazole or fluconazole for prophylaxis in severe graft-versus-host disease. $N$ Engl J Med. 2007;357(4):335-347.

130. Marr KA, Crippa F, Leisenring W, et al. Itraconazole versus fluconazole for prevention of fungal infections in patients receiving allogeneic stem cell transplants. Blood. 2004;103(4):1527-1533.

131. Van Burik JA, Ratanatharathorn V, Stepan DE, et al. Micafungin versus fluconazole for prophylaxis against invasive fungal infections during neutropenia in patients undergoing hematopoietic stem cell transplantation. Clin Infect Dis. 2004;39(10):1407-1416.

132. Marr KA, Seidel K, Slavin MA, et al. Prolonged fluconazole prophylaxis is associated with persistent protection against candidiasis-related death in allogeneic marrow transplant recipients: Long-term follow-up of a randomized, placebo-controlled trial. Blood. 2000;96(6):2055-2061

133. Peel M, Mamai A, Fan W, et al. New beta-1,3-glucan synthase (GS) inhibitors with potent antifungal activity. Abstract presented at the 49th Interscience Conference on Antimicrobial Agents and Chemotherapy, San Francisco, CA, September 12-15, 2009.

134. Perkhofer S, Lechner V, Lass-Florl C. In vitro activity of isavuconazole against Aspergillus species and zygomycetes according to the methodology of the European Committee on Antimicrobial Susceptibility Testing. Antimicrob Agents Chemother. 2009;53(4): 1645-1647.

135. Watanabe N, Horii T, Miyazaki M, Hata K. E1210, a new broadspectrum antifungal, inhibits glycosylphosphatidylinositol (GPI) biosynthesis and effects Candida albicans cell characteristics. Abstract F1-841 presented at the 50th Interscience Conference on Antimicrobial Agents and Chemotherapy, Boston, MA, September 12-15, 2010.

136. Miyazaki M, Horii T, Hata K, Watanabe N. In vitro antifungal activity of E1210: A novel antifungal with activity against clinically important yeasts and moulds. Abstract F1-840 presented at the 50th Interscience Conference on Antimicrobial Agents and Chemotherapy, Boston, MA, September 12-15, 2010.

137. Warn PA, Sharp A, Gould J, et al. Efficacy of FG3409 a new antifungal agent, in reducing tissue burden in murine models of disseminated aspergillosis. Abstract F1-1182 presented at the 48th Interscience Conference on Antimicrobial Agents and Chemotherapy, Washington, DC, October 25-28, 2008.
138. Law D, Fothergrill AW, Chen SC, Sorrell TC, Birch M. The activity of FG3622 and FG3409 against Scedosporium spp. Abstract F1-858 presented at the 50th Interscience Conference on Antimicrobial Agents and Chemotherapy, Boston, MA, September 12-15, 2010.

139. Krysan D, Baxter BK, Didone L. Phosphoinositide-dependent kinase 1 (PDK1) inhibitors are a novel class of cell wall-targeted antifungal small molecules. Abstract F1-859 presented at the 50th Interscience Conference on Antimicrobial Agents and Chemotherapy, Boston, MA, September 12-15, 2010.

140. Nguyen D, Li J, Akache B, et al. MGCD290: A novel small molecule, modulates azole antifungal activity through specific inhibition of the histone deacetylase HOS2. Abstract M-1919 presented at the 49th Interscience Conference on Antimicrobial Agents and Chemotherapy, San Francisco, CA, September 12-15, 2009

141. Krishnan-Natesan S, Swaminathan S, Chandrasekar P. Extended spectrum triazole plus type II topoisomerase inhibitor (TI) against azole-resistant (R) isolates of Aspergillus: Synergistic interaction in vitro. Abstract M-396 presented at 50th Interscience Conference on Antimicrobial Agents and Chemotherapy, Boston, MA, September 12-15, 2010.

142. McKee J, Rabinow B, Cook C, Gass J. Nanosuspension formulation of itraconazole eliminates the negative inotropic effect of Sporanox in dogs. J Med Toxicol. 2010;6(3):331-336.

143. Segal BH, Kwon-Chung J, Walsh TJ, et al. Immunotherapy for fungal infections. Clin Infect Dis. 2006;42(4):507-515.

144. Romani L. Cell mediated immunity to fungi: A reassessment. Med Mycol. 2008;46(6):515-519.

145. Cenci E, Mencacci A, Bacci A, Bistoni F, Kurup VP, Romani L. T cell vaccination in mice with invasive pulmonary aspergillosis. J Immunol. 2000;165(1):381-388.

146. Beck O, Koehl U, Tramsen L, et al. Enumeration of functionally active anti-Aspergillus T-cells in human peripheral blood. J Immunol Methods. 2008;335(1-2):41-45.

147. Perruccio K, Tosti A, Burchielli E, et al. Transferring functional immune responses to pathogens after haploidentical hematopoietic transplantation. Blood. 2005;106(13):4397-4406.

148. Ito JI, Lyons JM. Vaccination of corticosteroid immunosuppressed mice against invasive pulmonary aspergillosis. J Infect Dis. 2002; 186(6):869-871.

149. Bozza S, Gaziano R, Lipford GB, et al. Vaccination of mice against invasive aspergillosis with recombinant Aspergillus proteins and $\mathrm{CpG}$ oligodeoxynucleotides as adjuvants. Microbes Infect. 2002;4(13):1281-1290.

150. Bozza S, Montagnoli C, Gaziano R, et al. Dendritic cell-based vaccination against opportunistic fungi. Vaccine. 2004;22(7):857-864.

151. Cassone A. Fungal vaccines: Real progress from real challenges Lancet Infect Dis. 2008;8(2):114-124.
Clinical Epidemiology

\section{Publish your work in this journal}

Clinical Epidemiology is an international, peer-reviewed, open access journal focusing on disease and drug epidemiology, identification of risk factors and screening procedures to develop optimal preventative initiatives and programs. Specific topics include: diagnosis, prognosis, treatment, screening, prevention, risk factor modification, systematic

\section{Dovepress}

reviews, risk \& safety of medical interventions, epidemiology \& biostatical methods, evaluation of guidelines, translational medicine, health policies \& economic evaluations. The manuscript management system is completely online and includes a very quick and fair peer-review system, which is all easy to use. 